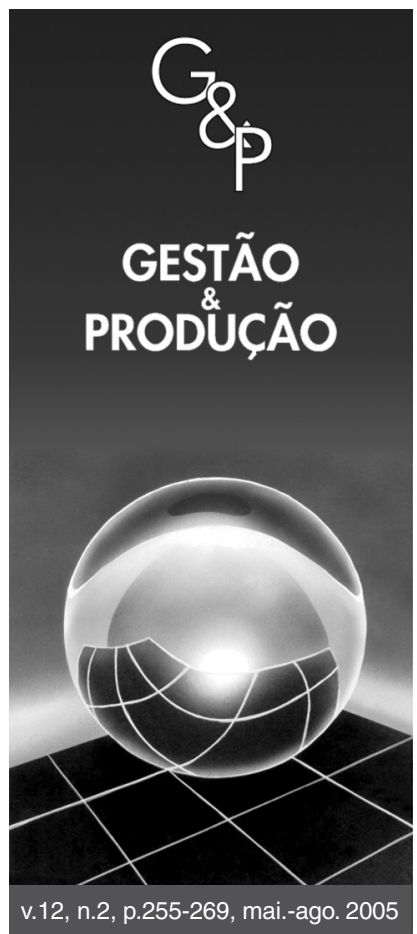

\title{
TRANSFERÊNCIA DE CONHECIMENTO TECNOLÓGICO: ESTUDO DE MÚLTIPLOS CASOS NA INDÚSTRIA FARMACÊUTICA
}

\author{
Vania Passarini Takahashi \\ Departamento de Ciências Farmacêuticas, \\ Faculdade de Ciências Farmacêuticas de Ribeirão Preto, USP, \\ Av. Zeferino Vaz, s/nº, CEP 14040-903, Ribeirão Preto, SP, \\ e-mail: vptakahs@usp.br
}

Resumo

Este artigo investiga os elementos críticos que afetam a habilidade das empresas farmacêuticas de desenvolverem suas capacidades tecnológicas operacionais e de aprendizagem dinâmica por meio de tecnologia importada. A informação obtida de estudos de casos em onze empresas, quatro no Canadá e sete no Brasil, mostra que todas as empresas adquiriram capacidade operacional em todos os estágios tecnológicos de desenvolvimento e produção de medicamentos, o mesmo não acontecendo quanto à capacidade de aprendizagem dinâmica. Mais especificamente, os resultados indicam que o desenvolvimento de capacidade operacional é afetado principalmente pelas capacidades gerenciais (de comunicador, de coordenador, de instrutor e de negociador) e pela cultura de aprendizagem. Também os estudos de casos indicam que o desenvolvimento de capacidade de aprendizagem dinâmica é influenciado pelo modo de transferência (cooperação científica e de licenciamento), pelas capacidades gerenciais (de empreendedor, de líder, de comunicador e de instrutor), pelo nível de capacidade de absorção e pela natureza da tecnologia importada.

Palavras-chave: transferência de tecnologia, capacidades tecnológicas, capacidades gerenciais, empresas farmacêuticas.

\section{Introdução}

A indústria farmacêutica tem o papel de curar, melhorar a qualidade de vida, minimizar a dor, prevenir doenças, trazer medicamentos inovadores com um objetivo essencial: prolongar a expectativa de vida. Em 1950, no Brasil, as pessoas viviam, em média, 43 anos. Hoje chegam aos 69 anos de vida. Atualmente, menos de $1 \%$ das mães transmite o vírus da AIDS para o filho, porque hoje existem 16 drogas para tratar a doença. Há 10 anos, existia apenas uma, e há 15 anos, nenhuma. Algumas doenças que praticamente eram tratadas com medicamentos foram desaparecendo, como a febre reumática, que hoje pode ser curada em $83 \%$ dos casos (Raimundo, 2001).

O consumo de medicamentos nos países vem aumentando a cada ano, sendo que o mercado farmacêutico mundial faturou, em 2002, a quantia de US\$ 370 bilhões
(IMS Health, 2003). Segundo dados da publicação do IMS Health (2003), em 2000, dos dez maiores mercados mundiais, os Estados Unidos mantinham a posição de líder com 41,3\%, seguido do Japão com 15,9\% e Alemanha com $5,5 \%$. O Brasil estava situado na $8^{\circ}$ posição, com $1,8 \%$ e o Canadá na $10^{\circ} \mathrm{com} 1,7 \%$ do mercado mundial.

Para se desenvolver e comercializar um novo medicamento, leva-se de 12 a 15 anos a um custo, em média, de US\$ 600 milhões. Medicamentos mais eficazes e seguros implicam em uma sofisticação tecnológica crescente e em altos investimentos (Prabhu, 1999; Tapon e Thong, 1999). Tal sofisticação implica obter amplo domínio tecnológico. Este domínio tecnológico pode ser alcançado por meio de investimentos em pesquisa e desenvolvimento internos. No entanto, devido à enorme variedade de 
conhecimentos científico e tecnológico empregados para desenvolver os novos medicamentos, a importação destes conhecimentos tem se tornado uma prática comum nas empresas farmacêuticas (Bierly e Chakrabarti, 1996; McCutchen Jr. e Swamidass, 1998; Prabhu, 1999; Tapon e Thong, 1999).

Segundo Leonard-Barton (1995), o principal objetivo das empresas ao adquirirem conhecimento tecnológico externo é melhorar suas capacidades tecnológicas. Se tal objetivo for alcançado, significa que a tecnologia transferida externamente foi bem sucedida. Estudos mostram que a eficácia da aquisição de tecnologias externas depende de uma série de fatores, tais como: infra-estrutura, competição de mercado, modos de transferência, capacidades de absorção, treinamento, natureza da tecnologia, etc.

Desenvolver e melhorar as capacidades tecnológicas de uma empresa que desenvolve e produz não somente um produto, mas um bem social é de extrema relevância. Esta preocupação se faz ainda mais presente do ponto de vista de países em desenvolvimento. Nestes países, em geral, condições sociais, econômicas e tecnológicas restringem a ocorrência de inovações radicais, tornando fundamentalmente importante o sucesso da transferência de tecnologia que possibilite o aumento da capacidade tecnológica destes países, reduzindo sua dependência externa em relação ao melhoramento do processo de desenvolvimento e produção de novos medicamentos mais eficazes e, conseqüentemente, a diminuição dos gastos em saúde. No caso do Brasil, por exemplo, a dependência externa gera um déficit comercial da ordem de US $\$ 2,2$ bilhões por ano na cadeia de fármacos e medicamentos (FSP, 2004).

Um bom entendimento dos elementos críticos do processo de transferência de tecnologia que influenciam no desenvolvimento das capacidades tecnológicas pode ajudar as empresas a empreenderem mais eficazmente os projetos de transferência.

Visando contribuir com a presente temática, este trabalho tem como objetivo analisar um grupo de fatores e suas relações e como estes fatores podem influenciar o desenvolvimento de capacidades tecnológicas por meio de tecnologia importada, no âmbito de empresas farmacêuticas no Brasil e no Canadá. Para alcançar tal objetivo, construiu-se um modelo conceitual considerando-se os principais fatores provenientes da literatura.

O artigo é dividido em seis partes: A parte um: introdução; a parte dois apresenta uma revisão sobre a temática transferência de tecnologia no contexto de capacidade tecnológica; a parte três apresenta e desenvolve um modelo conceitual de relações entre a transferência de tecnologia e o desenvolvimento de capacidades tecnológicas, descrevendo cada elemento componente do mo- delo; a parte quatro descreve a metodologia do estudo, compreendendo um estudo de múltiplos casos em empresas farmacêuticas no Brasil e no Canadá; a parte cinco apresenta as variáveis do modelo conceitual, mostrando os dados e discutindo os resultados obtidos; e a parte seis apresenta as considerações finais.

\section{Revisão: Transferência de tecnologia e capacidade tecnológica}

O termo transferência de tecnologia pode ser definido como um processo entre duas entidades sociais, em que o conhecimento tecnológico é adquirido, desenvolvido, utilizado e melhorado por meio da transferência de um ou mais componentes de tecnologia, seja ele o próprio processo ou parte dele, com o intuito de se implementar um processo, um elemento de um produto, o próprio produto ou uma metodologia (Takahashi, 2002).

Duas são as condições mínimas para que ocorra uma efetiva transferência de tecnologia: o transferidor precisa estar disposto a transferir e o receptor precisa ter condições de absorver o conhecimento transferido.

Para Barbosa apud Souza e Fernandes (1997), as etapas de desenvolvimento da capacidade tecnológica dos países desenvolvidos podem ser resumidas em criação, adaptação, absorção e comércio. Nestes países, os empresários buscam substituir a exportação de seus produtos pela montagem de linhas de produção diretamente nos países em desenvolvimento, com a finalidade de amadurecer suas economias e manter o crescimento do sistema como um todo, tornando a transferência de tecnologia uma imposição do próprio processo de desenvolvimento. Nos países em desenvolvimento, as etapas de desenvolvimento da capacidade tecnológica ocorrem de maneira inversa, ou seja: comércio, absorção, adaptação e criação. Nestes países, o empresário inicia com o processo de negociar a tecnologia com seus detentores. A partir de então, e iniciada a fabricação, tentará absorver o conhecimento tecnológico, com o que será possível adaptá-lo às suas condições, redesenhando a função produção e procurando explorar o conhecimento adquirido para outras situações do processo produtivo. A etapa de adaptação é considerada uma fase de "quase criação", estando a um passo de alcançar a etapa criativa, inovando em produtos e processos.

A literatura demonstra que os autores caracterizam as etapas de desenvolvimento das capacidades tecnológicas de diferentes formas. Leonard-Barton (1995) identificou que, no caso das empresas multinacionais, a transferência de tecnologia para suas filiais lhes proporciona específicos níveis de domínio tecnológico, que permite o cultivo de quatro níveis de capacidades: 1) capacidade operacional; 2) capacidade de adaptar; 3) capacidade de co-desenvolver produtos e/ou processos com o fornece- 
dor; e 4) capacidade de desenvolver produtos e processos independentemente do fornecedor da tecnologia transferida. Recentemente, Kumar et al. (1999) identificaram três tipos de capacidades tecnológicas e suas sequiências de atividades: capacidade de investimento, capacidade operacional e capacidade de aprendizagem dinâmica.

Além destas tipologias diversas, os níveis de detalhes usados pelos autores também diferem substancialmente. Contudo, independentemente de qual seja a tipologia, o investimento (compra) da tecnologia por empresas gera, inicialmente, um fluxo de tecnologia geralmente caracterizado por meio de contrato. O importante para os receptores é que, a partir destes contratos e do uso, absorção e adaptação deles, consigam aumentar seu patamar tecnológico, atingindo um estágio tal de desenvolvimento, que, eles próprios, sejam capazes de realizar novos incrementos nos produtos e processos, podendo, inclusive, em algumas situações, desenvolver em conjunto com o fornecedor da tecnologia inicial ou até superá-lo. Evidentemente, para isso ocorrer é necessário que haja entre o desenvolvimento de uma capacidade e outra, um acúmulo e um processo contínuo de aprendizagem dentro da empresa receptora (Kumar et al., 1999; Okejiri, 2000; Casanueva, 2001; Takahashi, 2002).

Outros estudos têm identificado alguns fatores como sendo relevantes para o sucesso do desenvolvimento de capacidades tecnológicas a partir da transferência de tecnologia realizada pela empresa receptora (Al-Ghailani e Moor, 1995; Autio e Laamanen, 1995; Kumar et al., 1999; Okejiri, 2000; Lui e Jiang, 2001). Basicamente, os fatores podem ser categorizados em: modos de transferência, natureza da própria tecnologia, fatores internos (capacidade de absorção, experiência da empresa, disponibilidade de pessoal qualificado, características organizacionais da empresa, etc.) e fatores externos (papel do governo, sistema sócio-cultural, etc.). Cabe ressaltar que os fatores externos são levados em consideração, principalmente, nos trabalhos que analisam o desenvolvimento de capacidades tecnológicas de um país em desenvolvimento a partir de transferência de tecnologia (Kumar et al., 1999; Okejiri, 2000; Lui e Jiang, 2001).

Estas mesmas literaturas mostram, ainda, que o desenvolvimento das capacidades tecnológicas é determinado por uma combinação de fatores. No entanto, cada estudo, além de estabelecer a sua combinação de fatores, também analisa conjuntamente, empresas de diferentes setores, obtendo, assim, resultados generalizados, não se aprofundando na questão:

Como os fatores influenciam as empresas de cada setor específico? Por exemplo, Kumar et al. (1999) investigaram nas empresas de três setores de negócio na Indonésia (têxtil, calçados e eletrônico) o desenvolvimento de capacidades tecnológicas a partir de tecnologia trans- ferida. Neste estudo, os autores combinaram os fatores externos: envolvimento do governo, infra-estrutura, modos de transferência e os fatores internos: investimento em $\mathrm{P} \& \mathrm{D}$, disponibilidade de treinamento, qualificação dos empregados e atividades de planejamento e controle. Concluíram que o desenvolvimento das capacidades tecnológicas nas empresas da Indonésia era afetado pelos fatores: atividades de planejamento e controle, disponibilidade de pessoal qualificado, programas de treinamento e por um específico modo de transferência, o de licenciamento. No entanto, o estudo não esclarece quais fatores são mais influentes nas empresas do setor têxtil, quais no setor de calçados e quais no setor eletrônico.

Com o objetivo de estudar o desenvolvimento das capacidades tecnológicas no contexto da importação da tecnologia pelas empresas farmacêuticas, elaborou-se um modelo conceitual a partir destas considerações, o qual será apresentado a seguir.

\section{Modelo conceitual de desenvolvimento de capacidades tecnológicas}

Baseando-se nos estudos teóricos que classificam as capacidades tecnológicas adquiridas por transferência de tecnologia, criou-se um modelo conceitual de desenvolvimento de capacidades tecnológicas (Takahashi, 2002). Este permite avaliar o desenvolvimento de capacidades tecnológicas, considerando em qual estágio tecnológico do processo de desenvolvimento e/ou produção de medicamento a tecnologia foi adquirida. Uma importante característica do modelo é que a capacidade tecnológica é um processo contínuo de aprendizagem e a extensão da aprendizagem depende de uma combinação de variáveis, como ilustra a Figura 1.

\subsection{Capacidades tecnológicas}

Capacidade tecnológica é conceituada como o conhecimento acumulado e a habilidade de fazer, compreender,

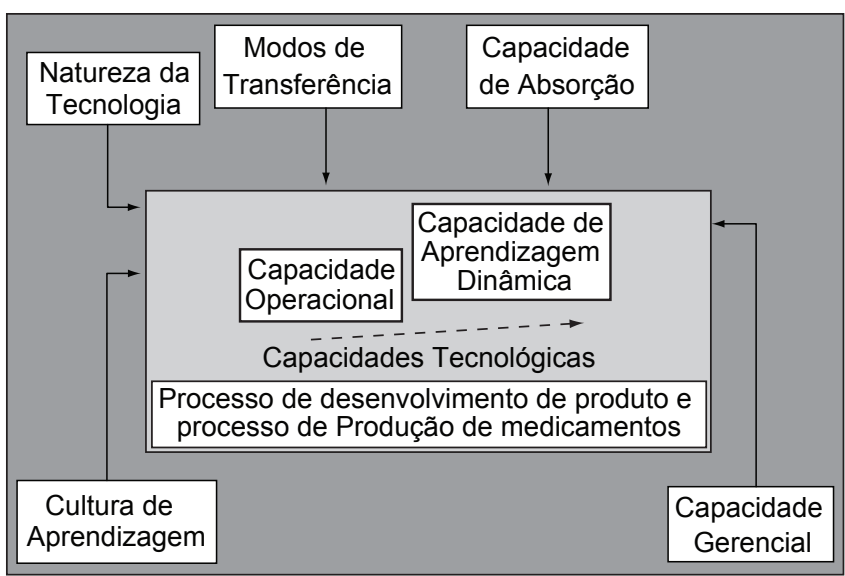

Figura 1. Modelo conceitual. 
utilizar e desenvolver estes conhecimentos para produzir novas tecnologias (Takahashi, 2002).

A partir das várias tipologias de capacidade tecnológica encontradas na literatura, foram identificados dois tipos considerados críticos no processo de transferência de tecnologia: a operacional e a de aprendizagem dinâmica (Kumar et al., 1999; Takahashi, 2002). A capacidade operacional consiste nas habilidades e informações necessárias para operacionalizar, manter e consertar a tecnologia, isto é know-how. Esse know-how pode ser obtido, principalmente, por meio de treinamento e de suporte técnico do fornecedor. Contudo, tal obtenção depende de conhecimentos prévios da empresa receptora, gerenciamento, envolvimento dos membros e de um ambiente voltado à aprendizagem (Cusumano e Elenkov, 1994; Takahashi, 2002).

A capacidade de aprendizagem dinâmica consiste nas habilidades e informações necessárias para gerar mudanças dinâmicas técnicas e organizacionais e para gerenciar as mudanças, isto é, know-why. Esta capacidade permite ao receptor replicar, alterar os conhecimentos técnicos adquiridos, produzindo novos produto e processos, criando novos conhecimentos, isto é, ser inovativa. Sua aquisição ocorre por meio de um processo cumulativo de aprendizagem na organização.

Nesta pesquisa, a avaliação do desenvolvimento destas capacidades consiste em analisar o nível de absorção tecnológico alcançado em cada uma delas, considerando em qual estágio tecnológico do processo de desenvolvimento e/ou produção de medicamento a empresa as adquiriu pela tecnologia importada (Takahashi, 2002).

\subsection{Capacidade de absorção}

O desafio para a criação de novas configurações de conhecimento dentro das empresas implica na absorção de diferentes tipos de novos conhecimentos, o que se torna uma habilidade-chave para direcionar a gestão das empresas (Van Den Bosch et al., 1999). Conseqüentemente, como citado por Cohen e Levinthal (1990, p. 128), "a habilidade da empresa de reconhecer o valor de um novo conhecimento, assimilá-lo e aplicá-lo para fins comerciais é de importância estratégica fundamental". Esta habilidade foi conceituada por Cohen e Levinthal (1990) como capacidade de absorção da empresa. Ela tem como premissa que a empresa necessita ter um nível de conhecimentos prévios para absorver e usar novos conhecimentos. Este conhecimento prévio inclui conhecimentos básicos, como também podem ser conhecimentos de desenvolvimentos cientifica e tecnologicamente recentes no campo de atuação da empresa.

Segundo Cohen e Levinthal (1990), o investimento em pesquisa e desenvolvimento (P\&D) aumenta o estoque de conhecimento interno da empresa, assim como a natureza das tarefas diariamente realizadas pelos empregados altamente qualificados facilita o acesso a conhecimentos externos, por meio de seu network com outros pesquisadores e cientistas de outras empresas, institutos de pesquisa e universidades e da participação em conferências (Mangematin e Nesta, 1999). O número de patentes de uma empresa, considerando os resultados das atividades de $\mathrm{P} \& \mathrm{D}$, indica um conjunto de competências científicas que aumentam o valor da base de conhecimento (Mangematin e Nesta, 1999). A maioria das publicações (Leonard-Barton, 1995; Van Den Bosch et al., 1999), seguido do trabalho de Cohen e Levinthal (1990), considera o nível de conhecimento prévio como o determinante da "capacidade de absorção da empresa". Como exemplo de indicadores para medir o nível de capacidade de absorção da empresa, pode ser empregado, entre outros: investimento financeiro em P\&D, nível educacional dos empregados, número de patentes e existência de parcerias com institutos de pesquisa e/ou universidades (Cohen e Levinthal, 1990; Van Den Bosch et al., 1999). Nesta pesquisa, foram considerados estes mesmos indicadores para medir o nível de capacidade de absorção das empresas estudadas.

\subsection{Cultura de aprendizagem}

Um conceito simples, mas abrangente, de organizações que aprendem foi proposto por Garvin (1993), como o de organizações capacitadas em criar, adquirir e transferir conhecimentos e modificar seus comportamentos para refletir estes novos conceitos. Os conceitos adquiridos e desenvolvidos só demonstram seu verdadeiro valor se as organizações os aplicarem em seu comportamento e até os modificarem. Não há aprendizagem se os conceitos e idéias ficarem apenas na memória das organizações e não no dia-a-dia destas (Anand et al., 1998). Segundo Crossan et al. (1998), aprendizagem organizacional é um processo dinâmico. A aprendizagem ocorre o tempo todo e em todos os três níveis (indivíduo, grupo e organização).

Nas organizações voltadas à inovação e aprendizagem, a gestão das pessoas deve ser muito focada, pois é ela a sustentação de uma cultura de aprendizagem. Dentro desta gestão, podem-se destacar quatro políticas principais que devem ser repensadas como: planejamento de recursos humanos, sistema de carreira, sistemas de recompensas e sistemas de desenvolvimento pessoal (Ferrari e Takahashi, 1998).

O acúmulo de conhecimento e de capacidades tecnológicas é um processo que depende de um investimento sistemático em aprendizagem organizacional. Segundo Cusumano e Elenkov (1994), as aquisições de capacidade tecnológica, inclusive por meio de transferência de tecnologia internacional, são advindas principalmente de experiência e aprendizagem dentro das empresas.

A cultura de aprendizagem nesta pesquisa buscou identificar nas empresas estudadas o quanto o ambien- 
te favorece o acúmulo de conhecimento e, conseqüentemente, o desenvolvimento de capacidades tecnológicas.

\subsection{Modos de transferência da tecnologia}

A tecnologia é transferida por meio de diversos modos de transferência (Al-Gahailani e Moor, 1995). O modo de transferência refere-se ao contrato realizado entre o fornecedor e o receptor da tecnologia.

Os diferentes modos de transferência (licenciamento, cooperação de pesquisa, turnkey, joint-venture, investimentos estrangeiros diretos, etc.) auxiliam a empresa receptora da tecnologia a aprender e a desenvolver novos conhecimentos, habilidades e capacidades tecnológicas (Lei, 1997).

Pesquisadores citam que existe uma relação entre a profundidade de conhecimento tecnológico e os modos de transferência (Cusumano e Elinkov, 1994; Autio e Laamanen, 1995; Boarini, 1999; Kumar et al., 1999). Por exemplo: joint-venture é tipicamente usado para adquirir conhecimentos embutidos na organização e licenciamento, permitindo transferir mais conhecimento codificado. Além disso, a quantidade de capacidade tecnológica transferida depende em particular do modelo escolhido (Cusumano e Elenkov, 1994; Bierly III e Chakrabarti, 1996; Kumar et al., 1999). Por exemplo, menos conhecimento é transferido em um modo turnkey do que em um de investimento estrangeiro direto.

Segundo Steensma (1996), a atividade funcional (pesquisa, desenvolvimento de produto/processo, produção, marketing) em que irá ocorrer a transferência, também deve ser levada em consideração ao ser escolhido o modo de transferência. O trabalho de Fitzgerald (1992) mostra que, no processo de desenvolvimento de um medicamento, o modo de licenciamento pode proporcionar um maior risco de insucesso quando utilizado nos estágios de descobrimento e testes pré-clínicos, porque as novas metodologias para produção de fármacos podem não alcançar o resultado esperado pela empresa receptora, que almeja a obtenção de um novo fármaco com potencial para o desenvolvimento de uma nova linha de produtos a serem produzidos pela empresa.

$\mathrm{Na}$ indústria farmacêutica, os modos mais comuns são: cooperação científica, licenciamento, joint ventures, investimentos estrangeiros diretos, turnkey (Fitzgerald, 1992; Bierly III e Chakrabarti, 1996; Mccuthen Jr e Swamidass, 1998). As empresas estudadas nesta pesquisa utilizaram, principalmente, os modos de transferência, turnkey, licenciamento, cooperação de pesquisa e investimento estrangeiro direto, nas áreas funcionais de desenvolvimento de produto/processo e produção de medicamentos.

\subsection{Natureza da tecnologia}

A extensão com que a empresa realmente internaliza novas habilidades e técnicas, pode ser parcialmente de- pendente dos atributos ou características da tecnologia (Autio e Laamanen, 1995; Steensma, 1996).

Uma das características sobre a natureza da tecnologia considerada relevante no processo de transferência é seu nível de maturidade (idade da tecnologia). Quanto mais madura se torna a tecnologia no mercado, maior o número de indivíduos familiarizados com seus conceitos e aplicação e, como consequiência, aumentam as chances da empresa receptora da tecnologia adquirir novas capacidades (Al-Ghailani e Moor, 1995; Mansfield, 2000).

Duas dimensões quanto à natureza da tecnologia foram analisadas por Steensma (1996): complexidade técnica e mudança sistêmica. A complexidade técnica é inerente à sofisticação da tecnologia. Ela indica a percepção da complexidade da empresa em relação à nova tecnologia. Quanto maior a percepção da complexidade, ou seja, quanto maior o nível de sofisticação da tecnologia, mais difícil a comunicação entre as partes envolvidas e, portanto, maior a dificuldade da empresa receptora de desenvolver capacidade tecnológica. A mudança sistêmica refere-se ao contraste entre a nova tecnologia adquirida e àquelas existentes na empresa receptora, ou seja, quanto de experiência a empresa receptora tem com a tecnologia similar àquela importada.

A diferença crítica entre estas duas dimensões é a extensão à qual elas variam ao redor da empresa receptora da nova tecnologia (Steensma, 1996). A complexidade técnica é externa ao domínio de controle da organização. Nada pode ser feito para alterar o grau de complexidade de uma tecnologia. Entretanto, o grau de mudança sistêmica é dependente da experiência tecnológica interna da empresa e, conseqüentemente, variará de empresa para empresa. Ambas as dimensões influenciarão a facilidade pela qual o conhecimento será absorvido e incorporado à organização (Autio e Laamanen, 1995; Steensma, 1996).

Neste estudo, a natureza da tecnologia foi analisada, considerando-se a percepção da tecnologia adquirida, quanto à sua sofisticação tecnológica e sua similaridade com as tecnologias já existentes na empresa receptora.

\subsection{Capacidades gerenciais}

No novo contexto organizacional, gestores de todos os níveis estão sendo "lembrados" da sua influência quanto à evolução das capacidades da empresa e, conseqüentemente, da sua contribuição para a melhoria do desempenho organizacional (Floyd e Wooldridge, 1997; Chapman, 2001).

A capacidade gerencial compreende uma série de habilidades, conhecimentos e experiências que uma pessoa deve ter para desempenhar certas funções gerenciais eficazmente (Mintzberg, 1994; Floyd e Wooldridge, 1997).

Estudos realizados para analisar o perfil dos gestores de pesquisa e desenvolvimento e de projetos, como Shtub 
et al. (1994) e Rabechini (2001), identificaram um conjunto de habilidades consideradas relevantes: construção de equipes, liderança, resolução de conflitos, competência técnica, planejamento, empreendedorismo, alocação de recursos, negociação, comunicação e relações interpessoais.

Na mesma linha dos trabalhos de Mintzberg (1994), Quinn et al. apud Belasen (2000), identificaram-se oito papéis que devem ser utilizados pelo gestor em cada situação que se faça necessário: coordenador, monitor, facilitador, mentor, inovador, negociador, produtor e diretor. Além disso, para cada papel, os autores identificaram um conjunto de três competências essenciais, para um desempenho eficaz das tarefas a serem realizadas.

Vários autores citam que sem habilidades de gerenciamento é impossível organizar a empresa para receber, utilizar e explorar os conhecimentos tecnológicos adquiridos externamente (Fitzgerald, 1992; Cusumano e Elenkov, 1994; Bessant e Rush, 1995; Leonard-Barton, 1995; Chapman, 2001).

Sendo assim, por meio dos estudos acima mencionados, buscaram-se as habilidades e os papéis inerentes ao gestor que seriam os mais importantes ao profissional responsável pelo projeto de transferência de tecnologia, tais como: líder, negociador, empreendedor, coordenador, instrutor, comunicador e habilidade técnica.

\section{Metodologia}

O presente trabalho é baseado na metodologia de estudos de casos múltiplos. Tal metodologia é a mais recomendada para se descrever e avaliar situações quando a questão de pesquisa é do tipo "como", em que o pesquisador não tem nenhum controle sobre o evento, e quando se está buscando ampliar o conhecimento a respeito de determinado tema (Yin, 1994). Foram escolhidos estudos de casos de forma não-probabilística, do tipo intencional. Neste sentido, foram selecionadas intencionalmente sete empresas farmacêuticas no Brasil e quatro empresas no Canadá. Empresas do Canadá acrescentadas na amostra, visam possibilitar e identificar a existência ou não de algum contraponto esclarecedor à experiência das empresas do Brasil.

A escolha das empresas foi baseada nos seguintes fatores: 1) empresas farmacêuticas conceituadas no seu mercado de atuação, tanto no segmento de mercado quanto na classe terapêutica; 2) empresas que desenvolvem e/ou produzem medicamentos para uso humano; 3 ) empresas com experiência anterior em pelo menos um projeto de transferência de tecnologia; e 4) empresas que desenvolveram ou estavam desenvolvendo nos últimos cinco anos um projeto de transferência de tecnologia.

Para a coleta de dados, o instrumento básico adotado foi o questionário, composto de questões relacionadas às características gerais da empresa, do projeto de transferência e das variáveis estudadas (segundo o modelo conceitual). As perguntas eram do tipo fechadas e abertas. $\mathrm{O}$ processo de coleta foi complementado pelo procedimento de entrevista. Participou do estudo uma pessoa de cada empresa, necessariamente o responsável pelo projeto de transferência de tecnologia e diretamente envolvido, desde seu início até sua finalização.

\subsection{Variáveis, medidas e estrutura de análi- se dos dados}

$\mathrm{Na}$ abordagem teórica deste trabalho, apresentou-se um modelo conceitual (Figura 1). No Quadro 1, estão apresentadas as variáveis que estão sendo consideradas para este estudo.

Para a análise e interpretação dos dados das variáveis do modelo conceitual, foi utilizada a média ponderada como instrumento estatístico no estudo da cultura de aprendizagem, capacidade gerencial, natureza da tecnologia e capacidade tecnológica. Para a cultura de aprendizagem, foram atribuídos valores aos diferentes graus de concordância, dentro de uma escala Likert de 1 (discordo totalmente) a 5 (concordo totalmente). Para a capacidade gerencial, foram conferidos valores aos diferentes graus de concordância nas habilidades de gerenciamento do projeto de transferência de tecnologia (coordenador, comunicador, líder, negociador, empreendedor, instrutor e técnica) utilizando-se a escala Likert de 1 (não totalmente competente) a 5 (totalmente competente). Assim, pode-se estabelecer como critério que os valores acima de 3 significam a influência das variáveis para o estabelecimento de um ambiente favorável na empresa, para que as capacidades tecnológicas possam ser desenvolvidas a partir do projeto de transferência, e os abaixo de 3, a não influência das variáveis. Ainda em relação à capacidade gerencial, buscou-se identificar o perfil do entrevistado. Quanto à natureza da tecnologia, empregou-se a escala Likert de 1 (discordo totalmente) a 5 (concordo totalmente). O critério estabelecido permite considerar que valores acima de 3 significam que o nível de percepção da sofisticação e similaridade da tecnologia transferida não dificulta o desenvolvimento da capacidade tecnológica, e os abaixo de 3, o nível de percepção indica que dificulta. Em relação à capacidade tecnológica, utilizou-se a escala Likert de 1 (muito baixo domínio) a 5 (muito alto domínio). Neste caso, pode-se estabelecer como critério que os valores acima de 3 significam que a empresa obteve o domínio da tecnologia e desenvolveu uma nova capacidade, e os valores abaixo deste, a empresa não obteve domínio.

Na variável capacidade de absorção, a estrutura de questões e das respostas permite uma adequada compreensão dos resultados obtidos em percentagens e valores inteiros. Assim, quanto mais altos os valores, maiores 
Quadro 1. Descrição das variáveis e suas medidas.

\begin{tabular}{|c|c|}
\hline Variável & Descrição da variável e medidas \\
\hline $\begin{array}{l}\text { Capacidade de } \\
\text { Absorção }\end{array}$ & $\begin{array}{l}\text { Investimento em P\&D como um percentual do total das vendas (ano). } \\
\text { Mestres e doutores como uma proporção do total de empregados da empresa. } \\
\text { Número de parcerias com institutos de pesquisa e/ou universidade. } \\
\text { Número de patentes geradas por ano. }\end{array}$ \\
\hline $\begin{array}{l}\text { Capacidade } \\
\text { Gerencial }\end{array}$ & $\begin{array}{l}\text { Negociador: eficiência na negociação com o fornecedor quanto à prestação do serviço; eficiência na negociação } \\
\text { com o grupo para a realização das tarefas. } \\
\text { Empreendedor: encorajar a inovação e experimentação; encorajar o grupo a usar novas técnicas de solucionar } \\
\text { problemas; criar ambiente de desafio; ajudar os empregados a se adaptarem ao ambiente de risco e incerteza. } \\
\text { Líder: auxiliar o grupo a tomar decisões; auxiliar na solução de problemas; mobilizar esforços do grupo; moti- } \\
\text { var o grupo a persistir nas dificuldades; obter suporte e compromisso dos superiores e ter sensibilidade cross- } \\
\text { cultural. } \\
\text { Coordenador: construir grupos multidisciplinares; gerenciar conflitos; delegar tarefas; delegar decisões sobre } \\
\text { os aspectos técnicos do projeto; gerenciar cooperação entre as várias funções envolvidas no projeto; organizar } \\
\text { recursos humanos, materiais e serviços. } \\
\text { Instrutor: analisar o progresso de cada fase do projeto; fomentar o aprendizado e o desenvolvimento dos indi- } \\
\text { víduos por meio de treinamento; fomentar o aprendizado ocorrido com o projeto entre os membros do grupo e } \\
\text { fomentar o aprendizado ocorrido com o projeto do grupo para a empresa. } \\
\text { Comunicador: explicar com clareza aos empregados os benefícios do projeto em alcançar os objetivos da } \\
\text { empresa; comunicar (escrita e oralmente) as instruções e solicitações para o grupo realizar o projeto; gerenciar } \\
\text { problemas de comunicação entre grupo de P\&D, grupo de manufatura, grupo de suporte técnico e o fornecedor } \\
\text { da tecnologia. } \\
\text { Técnica: credibilidade técnica com cientistas/engenheiros/farmacêuticos; entender as tecnologias e as tendên- } \\
\text { cias; participar na busca para integrar soluções e inovações tecnológicas. } \\
\text { Perfil do entrevistado responsável pelo projeto de transferência: posição que ocupa na empresa, experiência } \\
\text { na empresa e na função atual, qualificação, experiência com projetos de transferência. }\end{array}$ \\
\hline $\begin{array}{l}\text { Cultura de } \\
\text { Aprendizagem } \\
\text { da Empresa }\end{array}$ & $\begin{array}{l}\text { Treinamentos são disponíveis rapidamente para melhorarem as habilidades e conhecimentos; lições apreendidas } \\
\text { por um grupo são ativamente compartilhadas com outros grupos, os valores e comportamentos evitam a síndro- } \\
\text { me do "não inventado aqui", empregados são capazes de romper com o conjunto de pensamentos tradicionais e } \\
\text { ver as coisas de uma perspectiva nova e diferente, o sistema de recompensa reconhece a contribuição feita pelos } \\
\text { empregados, etc. }\end{array}$ \\
\hline $\begin{array}{l}\text { Natureza da } \\
\text { Tecnologia }\end{array}$ & $\begin{array}{l}\text { Idade da tecnologia em anos (maturidade) } \\
\text { Grau de percepção quanto à sofisticação e similaridade da tecnologia adquirida: tecnologia fácil de ser usa- } \\
\text { da; tecnologia fácil de ser entendida, necessidade de aquisição de novos conhecimentos muito diferentes dos } \\
\text { existentes pela empresa para implantar a nova tecnologia, a nova tecnologia é muito similar às já existentes na } \\
\text { empresa. }\end{array}$ \\
\hline $\begin{array}{l}\text { Modos de } \\
\text { Transferência }\end{array}$ & $\begin{array}{l}\text { Modo escolhido: Licenciamento/Cooperação Científica/Turnkey/Investimento Estrangeiro Direto (IED) } \\
\text { Tempo de serviço prestado pelo fornecedor de tecnologia em meses: treinamento, reuniões, assessorias, etc. } \\
\text { Em qual estágio tecnológico do processo de desenvolvimento e produção do medicamento a tecnologia adquiri- } \\
\text { da foi aplicada. }\end{array}$ \\
\hline $\begin{array}{l}\text { Capacidade } \\
\text { Tecnológica }\end{array}$ & $\begin{array}{l}\text { Capacidade Operacional: nível de domínio da tecnologia em termos de operacionalizar e manter a tecnologia } \\
\text { transferida. } \\
\text { Capacidade de Aprendizagem Dinâmica: nível de domínio para modificar e inovar a tecnologia transferida. }\end{array}$ \\
\hline
\end{tabular}

são os indícios da existência de um ambiente favorável na empresa à assimilação e, principalmente, à criação de novos conhecimentos, e quanto mais baixos os valores, maiores são os indícios de um ambiente voltado mais à assimilação de conhecimentos do que à criação de um novo conhecimento.

Em relação à variável modo de transferência, as questões procuraram identificar qual o modo que as empresas escolheram para transferir a tecnologia, o tempo de prestação do serviço do projeto e em qual estágio tecnológico (processo de desenvolvimento de produto e/ou processo ou de produção de medicamentos) a tecnologia transferida foi aplicada.

\section{Resultados e análise dos estudos de casos}

\subsection{Características das empresas e dos projetos de transferência de tecnologia}

Foram realizados estudos de caso em onze empresas, sendo sete no Brasil e quatro no Canadá. As empresas no Brasil são indicadas pela letra B e as empresas no Cana- 
dá, pela letra C. As características das empresas estudadas estão apresentadas na Tabela 1.

\subsubsection{Segmentos de mercado}

O segmento dos medicamentos de marca envolve duas situações: a primeira (marca 1), está relacionada à inovação de um novo medicamento (produto patenteado). Nesta situação, os níveis de investimentos em P\&D (em torno de $18 \%$ das vendas) e a qualificação dos profissionais têm de ser elevados, proporcionando maior número de patentes de produtos e de processos, nos quais as empresas atuam em todos os estágios tecnológicos, desde o descobrimento até a comercialização (Queiroz, 1993). A segunda situação (marca 2), diz respeito ao descobrimento de novos mecanismos de liberação e absorção do fármaco pelo organismo e de novas formas farmacêuticas (comprimido, cápsulas, injetáveis, etc.) aumentando, assim, a eficácia do medicamento (patenteado) existente. Neste caso, tanto o investimento quanto o número de profissionais altamente qualificados é considerado menor que na primeira situação, e as empresas começam a atuar a partir dos testes clínicos (Ansel et al., 2000).

Nos segmentos de medicamentos genéricos e OTC, a inovação se concentra no desenvolvimento de novas formas farmacêuticas do medicamento e no processo de produção. No caso dos medicamentos genéricos, um investimento um pouco maior se faz necessário, quando comparado ao medicamento OTC, em função da necessidade de se realizarem os testes de bioequivalência e/ou biodisponibilidade para se comprovar que o medicamento tem a mesma eficácia do medicamento que detinha a patente original (Ansel et al., 2000).

Conforme ilustra a Tabela 1, as empresas estudadas no Brasil participam de mais de um segmento de mercado (medicamentos de marca 2/genérico; marca 2/OTC), enquanto que nas empresas no Canadá, o foco está principalmente no segmento de medicamentos de marcas 1 .

\subsubsection{Estágios tecnológicos de atuação das empresas}

Com exceção da empresa $\mathrm{C} 4$, as empresas estudadas no Canadá realizaram todos os estágios tecnológicos: desde o descobrimento de um novo fármaco, o desenvolvimento de um novo medicamento até a sua produção e comercialização.

Nas empresas do Brasil, todas executaram os estágios de produção e de comercialização de medicamentos. As empresas que realizaram os estágios de desenvolvimento e teste clínicos explicitaram que estão mais voltadas, principalmente, para o aperfeiçoamento de um fármaco existente do que propriamente ao desenvolvimento de um novo. Quanto a esta questão, verifica-se o inverso no caso das empresas estudadas no Canadá.

\subsection{Variáveis do modelo conceitual}

\subsubsection{Capacidade de absorção}

A Tabela 2 apresenta os valores resultantes das respostas obtidas nas empresas, referentes ao nível de capacidade de absorção. A dispersão dos dados deve ser analisada levando-se em consideração dois elementos: o segmento de atuação da empresa e o estágio tecnológico de atuação da empresa.

No caso das empresas estudadas no Brasil, a maioria atua em dois segmentos: genérico e marca-situação 2; OTC e marca-situação 2. Esta característica das empresas pesquisadas pode justificar os valores dos indicadores de capacidade de absorção: baixos investimentos em P\&D (média de menos de $4 \%$ ) e também um pequeno quadro de empregados altamente qualificados (média de 2\%). No caso das empresas no Canadá, principalmente aquelas que atuam com exclusividade no segmento de marca-situação 1 (C1, C2 e C4), os valores dos indicadores são altos: investimento em P\&D: média de $11 \%$ e empregados altamente qualificados: média de $25 \%$. Já no

Tabela 1. Características Gerais das Empresas.

\begin{tabular}{clll}
\hline Empresa & Capital & \multicolumn{1}{c}{ Segmento } & Estágio Tecnológico de Atuação da Empresa \\
\hline C1 & UK & Marca (1) & Descobrimento do fármaco até a comercialização \\
C2 & Canadá & Marca (1) & Descobrimento do fármaco até a comercialização \\
C3 & EUA & Marca (2)/OTC & Descobrimento do fármaco até a comercialização \\
C4 & Canadá & Marca (1) & Descobrimento do fármaco até testes clínicos \\
B1 & EUA & Marca (2)/OTC & Testes clínicos até a comercialização \\
B2 & BRA & OTC & Produção de medicamentos até comercialização \\
B3 & EUA & Marca (2)/OTC & Produção de medicamentos até comercialização \\
B4 & BRA & Marca (2)/genérico/OTC & Descobrimento de fármaco até comercialização \\
B5 & BRA & Marca (2)/genérico & Descobrimento de fármaco até comercialização \\
B6 & BRA & Marca (2)/genérico & Testes clínicos até a comercialização \\
B7 & EUA & Marca (2)/OTC & Produção de medicamentos até comercialização \\
\hline
\end{tabular}

OTC (over-the-counter): medicamentos de venda livre nos balcões das farmácias

Marca (1) (2) e Genérico: medicamentos vendidos sob prescrição médica 
caso da empresa C3, que atua em dois segmentos (OTC e marca-situação 2), estes índices são menores e mais próximos à situação encontrada nas empresas do Brasil, que participam de dois segmentos. Ainda em relação a esta questão, é possível verificar que o número de patentes é maior no caso das empresas que participam somente do segmento de marca do que daquelas que participam de mais de um segmento. Os resultados também indicam, na média, que tanto as empresas do Brasil quanto as do Canadá investem em parcerias com universidade e/ou institutos de pesquisa.

Altos investimentos em atividades de $\mathrm{P} \& \mathrm{D}$, empregados altamente qualificados e parcerias com universidades/institutos de pesquisa possibilitam à empresa aumentar seus estoques de conhecimento fundamental e interno, permitindo a geração de patentes. Segundo os trabalhos de Cohen e Levinthal (1990) e Mangematin e Nesta (1999), quanto maiores forem estes índices em uma empresa, maior será sua capacidade de absorção, o que implica em uma condição permissiva para assimilar-se todo tipo de conhecimento e, principalmente, para criarem-se novos conhecimentos.

Os resultados dos índices de capacidade de absorção (Tabela 2) indicam que as empresas do Canadá (C1, C2 e C3) apresentam indícios de que são fortes detentoras da habilidade de criar novos conhecimentos, ou seja, de desenvolverem novos medicamentos. Assim, em um projeto de transferência, maior seria a habilidade destas empresas de, não somente, assimilar e aplicar os conhecimentos adquiridos externamente, como também, desenvolver novos a partir deste, isto é, desenvolverem as capacidades operacionais e de aprendizagem dinâmica. No caso, principalmente, das empresas no Brasil, os índices indicam maior predominância da habilidade, por parte destas empresas, de assimilar e aplicar novos conhecimentos adquiridos, principalmente, quanto ao aperfeiçoamento dos medicamentos, estando mais aptas ao desenvolvimento de capacidades operacionais.

\subsubsection{Cultura de aprendizagem}

Os resultados apresentados no gráfico (Figura 2), valores acima de 3,3 de média de concordância, evidenciam que as empresas se preocupam com a disseminação do conhecimento por toda a organização e com a criação de um ambiente que estimule os funcionários a buscarem novos conhecimentos interna e externamente, bem como investem em treinamento.

Em particular, no caso das empresas no Brasil, verificou-se que ainda existem algumas barreiras a serem eliminadas para se estimular ainda mais a cultura de aprendizagem, mais explicitamente nas empresas B2 e B3. As principais barreiras estariam relacionadas a certo grau de ressalva, por parte dos empregados, de compartilharem informações e conhecimentos entre os grupos e de romperem com o conjunto de pensamentos tradicionais. No caso das empresas estudadas do Canadá, estas características são opostas àquelas encontradas nas empresas no Brasil. Estas empresas estimulam os funcionários a buscarem novas formas de resolverem os problemas e de compartilharem suas descobertas com outros membros pertencentes ou não a sua equipe.

Os valores ilustrados na Figura 2 indicam que essa variável pode proporcionar um ambiente muito favorável ao desenvolvimento das capacidades tecnológicas. Assim, quanto mais alto for este valor, maior a possibilida-

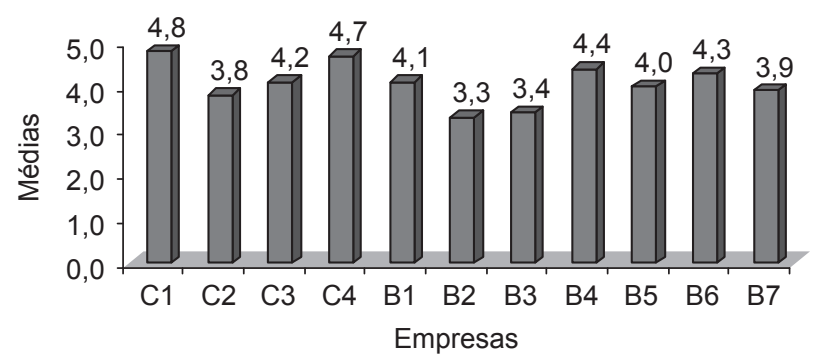

Figura 2. Níveis de cultura de aprendizagem das empresas.

Tabela 2. Indicadores dos níveis de capacidade de absorção das empresas.

\begin{tabular}{ccccc}
\hline Empresas & $\begin{array}{c}\text { \% investimento P\&D/ } \\
\text { vendas (ano) }\end{array}$ & $\begin{array}{c}\text { \% mestres e doutores/ } \\
\text { total de empregados }\end{array}$ & $\begin{array}{c}\mathbf{N}^{\mathbf{0}} \text { parcerias institutos de } \\
\text { pesquisa e/ ou universidade }\end{array}$ & $\begin{array}{c}\mathbf{N}^{\mathbf{0}} \text { patentes/ } \\
\text { ano }\end{array}$ \\
\hline C1 & $13,0 \%$ & $30,4 \%$ & 2 & 11 \\
C2 & $10,0 \%$ & $23,6 \%$ & 2 & 8 \\
C3 & $7,0 \%$ & $5,5 \%$ & 1 & 3 \\
C4 & $10,0 \%$ & $22,0 \%$ & 1 & 5 \\
B1 & $0,3 \%$ & $3,9 \%$ & 2 & 2 \\
B2 & $1,7 \%$ & $2,2 \%$ & 1 & 0 \\
B3 & $3,0 \%$ & $0,5 \%$ & 0 & 0 \\
B4 & $3,5 \%$ & $1,5 \%$ & 3 & 3 \\
B5 & $2,0 \%$ & $3,0 \%$ & 4 & 4 \\
B6 & $5,0 \%$ & $1,5 \%$ & 1 & 1 \\
B7 & $7,0 \%$ & $1,5 \%$ & 0 & 2 \\
\hline
\end{tabular}


de do desenvolvimento da capacidade de aprendizagem dinâmica.

\subsubsection{Modos de transferência de tecnologia}

Comparando-se as Tabelas 1 e 3, é possível constatar que os projetos de transferência foram aplicados nos estágios tecnológicos em que as empresas já possuíam experiências anteriores, com exceção da empresa B2, que realizou a transferência no estágio de descobrimento até então, muito pouco familiar às suas atuações.

As empresas estudadas são de capital nacional e estrangeiro, conforme ilustra a Tabela 1. Uma particularidade foi encontrada no caso das cinco empresas de capital estrangeiro (C1, C3, B1, B3 e B7), em que somente a empresa B3 realizou o processo de transferência normalmente realizado no interior de uma corporação multinacional, de matriz para filial. Para as demais empresas, o processo ocorreu fora do âmbito da matriz, com outras empresas farmacêuticas.

As empresas utilizaram principalmente os modos licenciamento, turnkey e cooperação científica. Particularmente nas empresas do Canadá, dois modos foram empregados: licenciamento e turnkey, e ambos aplicados nos estágios relacionados ao desenvolvimento de um novo fármaco (descobrimento, testes pré-clínicos e clínicos), que poderá ou não se transformar em um novo medicamento. No caso do Brasil, estes dois modos foram utilizados, mas nos estágios voltados principalmente à produção propriamente dita de uma nova linha de produtos e do desenvolvimento de novas formulações de medicamentos já existentes na empresa. Também se empregou o modo de cooperação científica, voltado ao desenvolvimento de novas metodologias para a identificação de outras possíveis utilizações de um determinado fármaco já existente, envolvendo os estágios de descobrimento, testes pré-clínicos e clínicos, estabelecimento da concentração do fármaco, dosagem e forma farmacêutica a ser empregada.

O tempo de prestação de serviço do fornecedor (treinamentos, assessorias, reuniões, etc.) após assinatura do contrato mostrou ser adequado para a maioria das empresas estudadas. As empresas que externaram alguma dificuldade quanto ao serviço foram aquelas que utilizaram o modo turnkey (C4 e B1) e o de licenciamento (B6 e B7). A empresa B1 explicitou que o tempo de prestação do serviço foi insuficiente, sendo necessário contratar consultores externos para a realização de treinamentos mais específicos quanto à utilização da tecnologia e, também, para auxílio na implementação e adaptação da nova tecnologia na empresa, relacionada à criação de uma nova linha de produtos a ser produzida. A empresa C4 teve problemas relacionados também à implementação $\mathrm{e}$ adaptação da tecnologia, mas citou que as dúvidas foram esclarecidas pelo fornecedor, não havendo a necessidade de contratação de consultores externos. As empresas B6 e B7 mencionaram, como problemas das atividades de assessoria, a demora em se obter respostas às dúvidas e falta de auxílio na solução dos problemas surgidos durante o período em que os "técnicos" não se encontravam no país, além da impossibilidade de se utilizarem serviços e comprarem insumos de outras empresas.

De acordo com os entrevistados, em particular as empresas do Brasil, que aplicaram os modos nos estágios de

Tabela 3. Características dos projetos de transferência.

\begin{tabular}{|c|c|c|c|c|}
\hline Empresa & $\begin{array}{c}\text { Prestação de } \\
\text { Serviço }\end{array}$ & $\begin{array}{c}\text { Modo de } \\
\text { transferência }\end{array}$ & Estágio tecnológico & $\begin{array}{c}\text { Uso de consultor } \\
\text { externo }\end{array}$ \\
\hline $\mathrm{C} 1$ & 6 meses & Turnkey & Descobrimento de fármacos & Não \\
\hline $\mathrm{C} 2$ & 18 meses & Licenciamento & $\begin{array}{l}\text { Co-desenvolvimento de métodos para pro- } \\
\text { dução de fármacos }\end{array}$ & Não \\
\hline $\mathrm{C} 3$ & 12 meses & Licenciamento & Testes clínicos e formulação & Não \\
\hline $\mathrm{C} 4$ & 6 meses & Turnkey & Descobrimento de fármacos & Não \\
\hline B1 & 6 meses & Turnkey & Produção industrial de medicamento & Sim \\
\hline B2 & $<36$ meses & $\begin{array}{l}\text { Cooperação científica univer- } \\
\text { sidade brasileira }\end{array}$ & $\begin{array}{l}\text { Desenvolvimento de novas aplicações do } \\
\text { fármaco }\end{array}$ & Não \\
\hline B3 & $<24$ meses & $\begin{array}{l}\text { Investimento estrangeiro } \\
\text { direto }\end{array}$ & Produção industrial de medicamento & Não \\
\hline B4 & $<48$ meses & $\begin{array}{l}\text { Cooperação científica univer- } \\
\text { sidade brasileira }\end{array}$ & Descobrimento de fármacos/ testes clínicos & Não \\
\hline B5 & 36 meses & $\begin{array}{l}\text { Cooperação científica univer- } \\
\text { sidade brasileira }\end{array}$ & $\begin{array}{l}\text { Testes clínicos até produção industrial de } \\
\text { medicamentos }\end{array}$ & Não \\
\hline B6 & 48 meses & Licenciamento & $\begin{array}{l}\text { Co-desenvolvimento de novas formas far- } \\
\text { macêuticas e produção de medicamentos }\end{array}$ & Não \\
\hline B7 & 10 meses & Licenciamento & Produção industrial de medicamentos & Não \\
\hline
\end{tabular}


produção de medicamentos, as dificuldades estão relacionadas a diferenças culturais, lingüísticas e dependência de insumos pertencentes ao fornecedor. Esta situação é apresentada pela literatura de transferência de tecnologia como um dos elementos que podem afetar, principalmente, as empresas de países em desenvolvimento bem como o sucesso do projeto de transferência, em função da própria dimensão tácita da tecnologia, pois, muitas vezes, não há interesse por parte do fornecedor em transferi-la, dimensão importantíssima que proporciona um ambiente voltado à mudança que influencia no desenvolvimento de capacidades de aprendizagem dinâmica.

\subsubsection{Natureza da tecnologia}

A Tabela 4 ilustra o grau de maturidade da tecnologia transferida pelas empresas estudadas. Percebe-se que nas empresas com projetos relacionados ao estágio de descobrimento/desenvolvimento ou testes clínicos $(\mathrm{C} 1$, C2, C3, C4, B2, B4, B5), as tecnologias adquiridas são recentes (entre 2 e 5 anos), enquanto que as tecnologias voltadas à produção industrial do medicamento $(\mathrm{B} 1, \mathrm{~B} 3$, B6 e B7) são tecnologias mais maduras, com aproximadamente 10 anos, exceção da empresa B1, com 5 anos.

Na Figura 3, são apresentadas as médias dos resultados concernentes à percepção da empresa quanto à sofisticação e similaridade da tecnologia adquirida. Os valores com média acima de 3,0 indicam que para as empresas não houve grande dificuldade quanto à utilização da nova tecnologia, no entanto, externaram que houve a necessidade de aquisição de novos conhecimentos para implementá-la. As empresas que sentiram maior dificuldade com a nova tecnologia $(\mathrm{C} 1, \mathrm{C} 2, \mathrm{~B} 1, \mathrm{~B} 2$ e B7) relacionaram esta dificuldade à não similaridade desta nova tecnologia com aquelas já existentes na empresa. Os resultados da Tabela 4 e da Figura 3 evidenciam a relação de que quanto mais nova for a tecnologia adquirida, também maior será seu grau de sofisticação e menor a sua similaridade com as tecnologias já existentes na empresa, implicando em uma dificuldade maior em se conseguir modificá-la e inovar a partir dela. Os valores obtidos quanto a esta característica da natureza da tecnologia indicam que esta variável pode influenciar o desenvolvimento de capacidades tecnológicas.

\subsubsection{Capacidade gerencial}

O perfil dos entrevistados das empresas demonstra que em sua grande maioria são executivos com alta experiência na posição que ocupam. Os entrevistados responsáveis pelo projeto de transferência demonstram ser conhecedores da política e da cultura de suas empresas. Dos onze entrevistados, somente os entrevistados das empresas C4, B2 e B3 participavam pela primeira vez de um projeto de transferência.

A Tabela 5 ilustra as notas ponderadas resultantes das respostas obtidas junto aos entrevistados que se auto-avaliaram e manifestaram sua importância, atribuída às suas competências relacionadas ao gerenciamento deste projeto de transferência em particular. De maneira geral, os valores descritos apresentam uma coerência do nível hierárquico com a qualificação do entrevistado. A avaliação dos resultados indica uma tendência genérica observada no sentido das competências das capacidades, consideran-

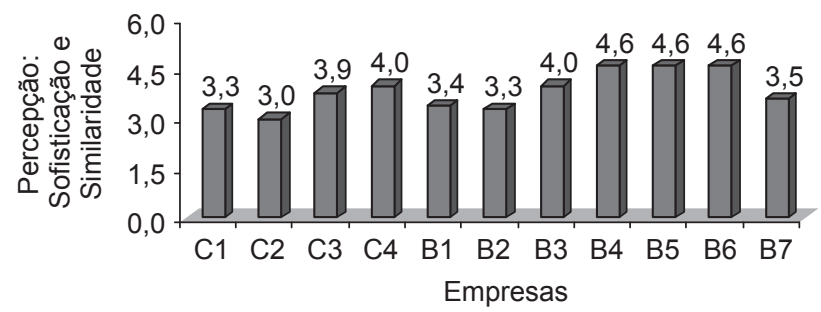

Figura 3. Nível de percepção das empresas quanto à sofisticação e similaridade da tecnologia transferida.

Tabela 4. Grau de maturidade de tecnologia transferida.

\begin{tabular}{cccccccccccc}
\hline & $\mathrm{C} 1$ & $\mathrm{C} 2$ & $\mathrm{C} 3$ & $\mathrm{C} 4$ & $\mathrm{~B} 1$ & $\mathrm{~B} 2$ & $\mathrm{~B} 3$ & $\mathrm{~B} 4$ & $\mathrm{~B} 5$ & $\mathrm{~B} 6$ & $\mathrm{~B} 7$ \\
\hline Idade da tecnologia $($ anos) & $<2$ & $<2$ & 4 & $<2$ & 5 & $<2$ & 10 & $<5$ & $<4$ & 10 & 10 \\
\hline
\end{tabular}

Tabela 5. Nível de competência nas capacidades gerenciais.

\begin{tabular}{llllllllllll}
\hline Competências & C1 & C2 & C3 & C4 & B1 & B2 & B3 & B4 & B5 & B6 & B7 \\
\hline Coordenador & 4,0 & 4,0 & 3,0 & 4,0 & 3,2 & 3,2 & 4,0 & 4,8 & 3,3 & 4,5 & 3,3 \\
Comunicador & 4,0 & 4,0 & 4,0 & 4,0 & 2,5 & 3,3 & 4,3 & 5,0 & 2,5 & 4,3 & 3,8 \\
Líder & 4,0 & 5,0 & 3,5 & 4,0 & 3,5 & 3,5 & 4,5 & 5,0 & 4,0 & 4,0 & 4,3 \\
Negociador & 4,0 & 2,0 & 4,0 & 3,0 & 3,5 & 2,0 & 4,0 & 4,5 & 3,5 & 3,8 & 3,6 \\
Empreendedor & 4,0 & 4,0 & 4,0 & 2,0 & 3,3 & 3,5 & 4,0 & 4,6 & 4,0 & 3,5 & 3,3 \\
Instrutor & 3,0 & 4,0 & 2,0 & 3,0 & 2,5 & 3,0 & 4,6 & 4,8 & 3,5 & 4,6 & 4,3 \\
Técnica & 3,0 & 5,0 & 4,0 & 2,0 & 4,0 & 3,5 & 4,7 & 5,0 & 4,3 & 3,3 & 5,0 \\
\hline
\end{tabular}


do-se a média das notas dadas: líder; técnica; comunicador; coordenador; empreendedor; instrutor; e negociador. Os valores obtidos demonstram que estas variáveis influenciam no estabelecimento de um ambiente favorável ao desenvolvimento das capacidades tecnológicas.

A capacidade de liderança possibilita ao gestor do projeto de transferência influenciar um grupo, com a criação de um ambiente de respeito mútuo, auxiliando-o a tomar decisões, motivando-o a estar totalmente envolvido, tornando o grupo mais consciente a respeito da importância e do valor dos resultados dos trabalhos; levando-o a ultrapassar seus próprios interesses em benefício da organização, habilidades fundamentais para a eficácia dos projetos . A capacidade técnica possibilita o entendimento das tecnologias e suas tendências e a identificação das tecnologias necessárias para que a empresa possa desenvolver novos produtos ou melhorá-los e, ainda, a localização destas novas oportunidades tecnológicas em outras empresas ou instituições de pesquisa. A capacidade de coordenação proporciona ao gestor a formação de um grupo interdisciplinar, a delegação de funções, a organização de recursos materiais e o gerenciamento de possíveis conflitos entre as partes envolvidas, necessárias às atividades do projeto de transferência. Durante o projeto, para que ocorra uma sinergia, as informações trocadas entre os grupos devem permitir que ambas as partes assimilem todas as instruções e solicitações. Portanto, gerenciar a comunicação, para que ela seja a mais clara possível, também possibilita o bom andamento do projeto. Além disso, para que os verdadeiros frutos com o projeto de transferência sejam colhidos pela empresa receptora, o processo de aprendizagem com a nova tecnologia deve ocorrer entre os membros internos do grupo e do grupo para com a organização. Neste sentido, a capacidade de instrutor pode proporcionar ao gestor fomentar este processo de aprendizado. A capacidade de empreender consiste em buscar, de forma deliberada, as fontes de experimentação e de inovação e de criar um ambiente de desafio entre os membros da empresa, estimulando-os a usarem novas técnicas de solucionar problemas. Negociação refere-se à capacidade do gestor de negociar com as várias entidades que participam do projeto, principalmente, quanto aos tipos de serviços que serão prestados pelo fornecedor e seu tempo de duração, bem como concentrar-se nos interesses e nos critérios objetivos do grupo e da organização.

Os resultados evidenciam que quanto maiores os níveis de competência gerencial dos entrevistados, maior será a contribuição para a habilidade da empresa em alcançar alto domínio tecnológico e, conseqüentemente, o desenvolvimento das duas capacidades tecnológicas, como apresentam os indícios das empresas $\mathrm{C} 1, \mathrm{C} 2, \mathrm{C} 3$, B3, B4, B5.

\subsubsection{Capacidades tecnológicas}

A Tabela 6 apresenta a média ponderada das capacidades operacional e de aprendizagem dinâmica, resultantes das respostas obtidas das empresas pesquisadas. Os resultados obtidos relativos à capacidade operacional, valores médios maiores que 3,7, indicam que todas as empresas desenvolveram esta capacidade. As empresas demonstram que o conhecimento tecnológico foi incorporado em alto nível em relação ao domínio para a operacionalização e manutenção da tecnologia, independente do estágio tecnológico do desenvolvimento e/ou produção de medicamentos. Também os resultados demonstram que não há uma diferença significativa quanto ao conhecimento absorvido e adquirido por meio da tecnologia importada entre as empresas do Brasil e as do Canadá, quanto à capacidade tecnológica operacional.

Em relação à capacidade de aprendizagem dinâmica, os valores médios encontram-se muito dispersos, variando de 1,5 a 4,6. As empresas C1, C2, C3, C4, B2, B4 e B5 apresentaram como resultados, valores médios acima de 3,0, o que significa que foi possível desenvolver esta capacidade. Uma característica comum destas empresas é que todas transferiram tecnologia nos estágios iniciais do processo de desenvolvimento do medicamento (descobrimento/testes pré-clínicos/testes clínicos). Todas estas empresas demonstraram que o conhecimento tecnológico foi incorporado em alto nível em relação ao domínio de modificar a tecnologia. Quanto ao domínio de inovar, somente as empresas C4 e B2 não o alcançaram. Já para as empresas B1, B3, B6 e B7 (valores abaixo de 3,0), o conhecimento adquirido não permitiu que elas desenvolvessem esta capacidade, nem sequer, quanto ao domínio de modificar a tecnologia. No caso destas empresas, a tecnologia transferida foi aplicada no estágio de produção de medicamento, relacionada principalmente a uma nova linha de produtos.

\section{Considerações finais}

Este trabalho procurou demonstrar o modo como o desenvolvimento de capacidades tecnológicas por meio de

Tabela 6. Nível das capacidades tecnológicas.

\begin{tabular}{|c|c|c|c|c|c|c|c|c|c|c|c|}
\hline Capacidades Tecnológicas & C1 & $\mathrm{C2}$ & C3 & $\mathrm{C4}$ & B1 & B2 & B3 & B4 & B5 & B6 & B7 \\
\hline Operacional & 4,3 & 4,0 & 4,0 & 4,7 & 3,7 & 4,0 & 4,5 & 4,7 & 4,0 & 4,7 & 4,7 \\
\hline Aprendizagem Dinâmica & 4,0 & 4,6 & 4,2 & 3,0 & 1,5 & 3,4 & 2,8 & 3,9 & 4,1 & 2,6 & 2,8 \\
\hline
\end{tabular}


transferência de tecnologia vem correndo nas empresas farmacêuticas. Em função desse objetivo, foi desenvolvido um modelo conceitual para analisar como os elementos capacidade de absorção, cultura de aprendizagem, natureza da tecnologia, modos de transferência e capacidade gerencial influenciam no desenvolvimento das capacidades operacional e de aprendizagem dinâmica.

Os resultados dos estudos de casos evidenciaram que o alto domínio da capacidade operacional foi alcançado por todas as onze empresas do estudo, enquanto que a capacidade de aprendizagem dinâmica, referente aos domínios de modificar e de inovar, foi alcançada somente em duas empresas no Brasil (B4 e B5) e em três no Canadá (C1, C2 e C3).

Os níveis de capacidade de absorção e de cultura de aprendizagem das empresas indicaram que todas possuíam conhecimentos tecnológicos prévios e um ambiente voltado à aprendizagem, requisitos básicos para se absorver e utilizar novos conhecimentos, ou seja, obter-se a capacidade operacional. Os resultados referentes à natureza da tecnologia transferida mostraram que uma tecnologia mais madura, menos sofisticada e com maior similaridade com as tecnologias existentes na empresa também aumentaram as possibilidades das empresas de adquirirem esta capacidade, principalmente, se foram aplicadas nos estágios de produção de medicamentos e nas fases de desenvolvimento de novas fórmulas farmacêuticas, como aconteceu na maioria das empresas estudadas do Brasil. Este veredicto é condizente com as pesquisas anteriores, que indicam que as tecnologias adquiridas voltadas aos melhoramentos não conseguem promover, nas empresas, ambientes de grandes mudanças técnicas, principalmente, no quesito de desenvolvimento de um produto radical, aqui, no caso, um medicamento novo. Ambientes de mudanças são necessários para se desenvolver a capacidade de aprendizagem dinâmica. Ao comparar as empresas do Brasil e as do Canadá, é evidente que maior nível de capacidade de absorção, de desenvolvimento de um ambiente voltado à aprendizagem e aquisição de tecnologias mais complexas aplicadas ao desenvolvimento de novos produtos, proporcionou um ambiente mais profícuo para o desenvolvimento de capacidade de aprendizagem dinâmica.

Em relação aos modos de transferência utilizados pelas empresas, há evidência de que sua influência no desenvolvimento das capacidades tecnológicas está relacionada aos estágios tecnológicos do medicamento e à duração da prestação de serviço. Aquelas empresas que transferiram tecnologia no estágio de produção do medicamento, utilizando o modo de licenciamento e cuja duração do serviço prestado pelo fornecedor foi maior que os modos de investimento estrangeiro direto e turnkey, alcançaram índices mais altos de capacidade operacional. No caso da transferência ter ocorrido nos estágios iniciais de desenvolvimento do medicamento (descobrimento, testes préclínico e testes clínico) os modos de licenciamento e de cooperação científica que apresentaram longo tempo de prestação de serviço também podem ter influenciado no fato de as empresas apresentarem índices mais altos de capacidade operacional e de aprendizagem dinâmica. As capacidades gerenciais de líder, técnica, coordenador e comunicador dos responsáveis pelos projetos de transferência possibilitaram influenciar no desenvolvimento das capacidades tecnológicas das empresas. Ainda em relação a este fator, apesar da amostra ser pequena, houve indício das capacidades de comunicador, empreendedor e de líder serem maiores entre os gestores das empresas do Canadá que as do Brasil. Estas capacidades podem ter estimulado a criação de um ambiente de mudanças que promoveu um maior desenvolvimento da capacidade de aprendizagem dinâmica das empresas do Canadá.

Este estudo apresenta limitações de ordem teórica e metodológica. No aspecto teórico, o fator limitante está relacionado ao fato deste trabalho não esgotar todas as variáveis pertinentes ao tema estudado. Quanto às limitações de ordem metodológica, devem-se considerar as restrições do método de estudo de múltiplos casos. Contudo, os resultados evidenciaram que as empresas que transferiram a tecnologia nos estágios iniciais de desenvolvimento de produto foram também as que desenvolveram a capacidade de aprendizagem dinâmica. No caso das empresas do Brasil, os resultados mostraram que o modo de transferência de cooperação científica permite às empresas aumentarem esta capacidade. Para que uma efetiva capacidade de inovação se desenvolva nas empresas do Brasil, é necessário, porém, um conjunto de ações por parte das instituições de pesquisa, poder público e das próprias empresas, como ocorre em países como o Canadá. As empresas precisam investir em empregados altamente qualificados e em pesquisa e desenvolvimento interno para aumentar seus níveis de capacidade de absorção, bem como aumentar a aproximação com laboratórios universitários. As instituições de pesquisa precisam buscar o conhecimento, enfocando-o também no desenvolvimento e na comercialização, reduzindo o excesso de burocracia e desenvolvendo instrumentos legais que regulamentem as atividades de pesquisa envolvendo universidades e empresas. Da mesma forma, por parte do poder público, faz-se necessário impulsionar, por meio de uma política industrial a criação de programas de financiamento específicos para este setor, como o Profarma. Deste modo, os benefícios poderão se estender pelo País todo, por meio de pesquisas de melhor qualidade, maiores e mais rápidas inovações tecnológicas no setor farmacêutico e conseqüente fortalecimento da economia nacional. 
AL-GHAILANI, H. H.; MOOR, W. C. Technology transfer to developing countries. International Journal Technology Management. v. 10, n. 7-8, p. 687-703, 1995.

ANAND, V., et al. An Organizational Memory Approach to Information Management. Academy of Management Review. v. 23, n. 4, p. 796-809, 1998.

ANSEL, H. C., et al. Farmacotécnica: formas farmacêuticas e sistemas de liberação de fármacos. 1 ed. São Paulo: Pioneira, 2000, 655 p.

AUTIO, E.; LAAMANEN, T. Measurement and evaluation of technology transfer: review of technology transfer mechanisms and indicators. International Journal Technology Management. v. 10, n. 7-8, p. 643-664, 1995.

BELASEN, A T. Leading the learning organization. 1 ed. New York: University of New York Press, 2000, 462 p.

BESSANT, J.; RUSH, H. Building bridges for innovation: the role of consultants in the technology transfer. Research Policy. v. 24, p. 97-114, 1995.

BIERLY III, P. E.; CHAKRABARTI, A. K. Technological learning, flexibility, and new product development in the pharmaceutical industry. IEEE Transactions on Engineering Management. v. 43, n. 4, p. 368-380. 1996.

BOARINI, E. Inbound technology transfer. In: SZAKONYI, R. Technology Management 1999. New York: Auerbach, 1999. p. 33-1-33-11.

CASANUEVA, C. The aquisition of firm technological capabilities in Mexico's open economy, the case of vitro. Technological Forecasting and Social Change. v. 66, p. 75-85, 2001.

CHAPMAN, J. A. The work of managers in new organisational contexts. The Journal of Management Development. v. 20, n. 1, p. 55-68, 2001.

COHEN, W. M.; LEVINTHAL, D. A. Absorptive capacity: a new perspective on learning and innovation. Administrative Science Quarterly. v. 35, p. 128-152. 1990.

CROSSAN, M. M., et al. Measuring organizational learning. Toronto: Richard Ivey School of Business. 1998 (Working Paper No 98-07).

CUSUMANO, M. A.; ELENKOV, D. Linking International technology transfer with strategy and management: a literature commentary. Research Policy. v. 23, p. 195-215, 1994.

FERRARI, F. M; TAKAHASHI, S. Troca de conhecimento entre equipes como fonte de inovação. In: Seminário de Gestíon Tecnológica, 4, 1998, Mérida. Anais ... Mérida: ALTEC, 1998. v.1.
FITZGERALD, J. D. Technology transfer issues in licensing pharmaceutical products. R\&D Management. v. 22, n. 3, p. 199-208, 1992.

FLOYD, S.; WOOLDRIDGE, B. Middle management's strategic influence and organizational performance, Journal of Management Studies. v. 34, n. 3, p. 465-485, 1997.

FSP. Política Industrial - Fármaco e informática sacam recursos. Folha de S. Paulo, São Paulo. 13 out. 2004. Folha Dinheiro, p. B2.

GARVIN, D.A. Building a learning organization. Harvard Business Review. Jul-Ago, p. 78-91, 1993.

IMS HEALTH. Worldwide pharmaceutical market. Disponível em: <http:// www.ims-global.com/globalinsights. $\mathrm{htm}>$. Acesso em: 10 setembro 2003.

KUMAR, V., et al. Building Technological Capability through importing technology: the case of Indonesian manufacturing industry. Journal of Technology Transfer. v. 24, p. 81-96, 1999.

LEI, D.T. Competence-building, technology fusion and competitive advantage: the key roles of organizational learning and strategic alliances. International Journal Technology Management. v. 14, n. 2-4, p. 208-237, 1997.

LEONARD-BARTON, D. Wellsprings of knowledge. 1 ed. Boston: Harvard Business School Press, 1995. 274 p.

LIU,H.; JIANG,Y. Technology transfer from higher education institutions to industry in China: nature and implications. Technovation. v. 21, p. 175-188, 2001.

MANGEMATIN, V.; NESTA, L. What kind of knowledge can a firm absorb? International Journal Technology Management. v.18, n. 3-4, p. 149-172, 1999.

MANSFIELD, E. Intellectual property protection, direct investment and technology transfer: Germany, Japan and the USA. The International Journal Technology Management. v. 19, n. 1-2, p. 3-21, 2000.

McCUTCHEN Jr., W. W.; SWAMIDASS, P.M. Explaining the differences in domestic and cross-boundary strategies alliances in the pharmaceutical biotech industry. International Journal Technology Management, Special Issue on Management of Technology in Health Care. p.490- 506. 1998.

MINTZBERG, H. Rouding out manager's job. Sloan Management Review. Fall, p. 14-26, 1994.

OKEJIRI, E. Foreign technology and development of indigenous technological capabilities in the Nigerian manufacturing industry. Technology in Society. v. 22, p. 189-199, 2000. 
PRABHU, G. N. Managing research collaborations as a portfolio of contracts: risk reduction strategy by pharmaceutical firms. International Journal Technology Management. v.18, n. 3-4, p. 207-231, 1999.

QUEIROZ, S. R. R. Estudo da competitividade da indústria Brasileira: competitividade da indústria de fármacos. Campinas: Unicamp, 1993. 133 p.

RABECHINI, R. J. A importância das habilidades do gerente de projetos. Revista de Administração. v. 36, n. 1, p. 92-100, 2001.

RAIMUNDO, J. Seminário Abifarma - Acesso aos Medicamentos no Brasil. Abifarma. Disponível em: <http:// www.abifarma.com.br/seminario $>$. Acesso em: 18 setembro 2001.

SHTUB, A., et al. Project management engineering technology and implementation. New Jersey: Prentice Hall, 1994.

SOUZA, A. A; FERNANDES, R. J. F. S. Telefone Público a Cartão indutivo telebrás: um vitorioso projeto de desenvolvimento e transferência de tecnologia brasileira. In: SEMINÁRIOS DE ADMINISTRAÇÃO, 2, 1997,
São Paulo. Anais ... São Paulo: SEMEAD, 1997. v.1. p. 554-564.

STEENSMA, H. K. Acquiring technological competencies through inter-organizational collaboration: an organizational learning perspective. Journal of Engineering and Technology Management. v. 12, p. 267-286, 1996.

TAPON, F.; THONG, M. Research collaborations by multi-national research oriented pharmaceutical firms: 19881997. R\&D Management. v. 29, n. 3, p. 219- 231, 1999.

TAKAHASHI, V. P. Capacidades tecnológicas e transferência de tecnologia: estudo de múltiplos casos da indústria farmacêutica no Brasil e no Canadá. 2002. 223 f. Tese (Doutorado em Engenharia Mecânica) - Escola de Engenharia de São Carlos, Universidade de São Paulo, São Carlos, 2002.

VAN DEN BOSCH, F.A.J., et al. Coevolution of firm absorptive capacity and knowledge environment: organizational forms and combinative capabilities. Organization Science. v. 10, n. 5, p. 551-568, 1999.

YIN, R. K. Case study research: design and methods. London: Sage Publications, 1994.

\title{
TRANSFER OF TECHNOLOGICAL KNOWLEDGE: A MULTIPLE CASE STUDY IN THE PHARMACEUTICAL INDUSTRY
}

\begin{abstract}
This article reports on an investigation into the critical elements affecting the ability of pharmaceutical companies to develop their technological operational and learning capabilities through imported technology. The information obtained from case studies at eleven companies, four in Canada and seven in Brazil, indicates that all the companies acquired operational technological capability in every technological stage of drug development and production, although this finding does not apply to their dynamic learning capacity. More specifically, the results indicate that the development of operational capability is affected mainly by management skills (communication, coordination, instruction and negotiation) and by the learning culture. These case studies also indicate that development of the capacity for dynamic learning is influenced by the mode of transfer (scientific cooperation and licensing), by management skills (entrepreneurship, leadership, communication and instruction), by the level of absorption capacity and by the nature of the imported technology.
\end{abstract}

Keywords: technology transfer, technological capability, management skills, pharmaceutical companies. 